\title{
Comparison of Intravenous Lignocaine and Dexmedetomidine for Attenuation of Hemodynamic Stress Response to Laryngoscopy and Endotracheal Intubation
}

\author{
Deepti N. Anandani¹, Manisha S. Kapdi², Ami D. Patel ${ }^{3}$, Pratik Jain ${ }^{4}$ \\ 1,2,3,4 Department of Anaesthesiology, Smt. NHL Municipal Medical College, Ahmedabad, Gujarat, India.
}

\section{ABSTRACT}

\section{BACKGROUND}

The purpose of the present study was to evaluate the efficacy of intravenous lignocaine $1.5 \mathrm{mg} / \mathrm{kg}$ \& intravenous dexmedetomidine $1 \mathrm{mcg} / \mathrm{kg}$ for attenuating the haemodynamic response to laryngoscopy \& endotracheal intubation in patients undergoing elective surgery under general anaesthesia.

\section{METHODS}

In this prospective randomised, comparative, clinical study, 60 patients were randomly divided into 2 groups, among them 30 patients were given infusion of 1.5 $\mathrm{mg} / \mathrm{kg}$ IV lignocaine, diluted to $10 \mathrm{ml}$ with normal saline, 3 minutes before intubation \& 30 patients were given infusion of dexmedetomidine $1 \mathrm{mcg} / \mathrm{kg}$ diluted to $25 \mathrm{ml}$ in normal saline over 10 minutes through infusion pump before induction. The heart rate, systolic blood pressure, diastolic blood pressure, mean arterial pressure, rate pressure product, oxygen saturation were measured at baseline, after study drug intubation at $\mathrm{L}+1, \mathrm{~L}+3, \mathrm{~L}+5, \mathrm{~L}+7 \& \mathrm{~L}+10$ ( $\mathrm{L}$ is onset of laryngoscopy). Statistical analysis was done by using descriptive \& inferential statistics using chisquare test, Students paired \& unpaired t test to find out the significance of the five variables namely mean heart rate (HR), mean systolic blood pressure (SBP), mean diastolic blood pressure (DBP), mean arterial pressure (MAP) and mean rate pressure product (RPP).

\section{RESULTS}

Dexmedetomidine provided better blunting of stress response during laryngoscopy and intubation without causing clinically significant respiratory depression, bradycardia or hypotension. It is better in achieving a low RPP, which is a good predictor of myocardial oxygen consumption. Dexmedetomidine provides better cardio-protection in patients against pressure response than lignocaine.

\section{CONCLUSIONS}

In these 60 patients, dexmedetomidine $(1 \mathrm{mcg} / \mathrm{kg}$ ) was found to be superior to lignocaine $(1.5 \mathrm{mg} / \mathrm{kg}$ ) for attenuation of pressor response.

\section{KEY WORDS}

Laryngoscopy, Endotracheal Intubation, Dexmedetomidine, Lignocaine, Rate Pressure Product
Corresponding Author:

Dr. Ami D. Patel,

Room No.13047/13th Floor,

SVP Hospital, Near Ellis Bridge,

Paldi, Ahmedabad, Gujarat, India.

E-mail:21amipatel@gmail.com

DOI: $10.14260 / \mathrm{jemds} / 2021 / 240$

How to Cite This Article:

Anandani DN, Kapdi MS, Patel AD, et al. Comparison of intravenous lignocaine and dexmedetomidine for attenuation of hemodynamic stress response to laryngoscopy and endotracheal intubation. J Evolution Med Dent Sci 2021;10(16): 1123-1129, DOI:

10.14260/jemds/2021/240

Submission 08-12-2020,

Peer Review 18-02-2021,

Acceptance 25-02-2021,

Published 19-04-2021.

Copyright (C) 2021 JEMDS. This is an open access article distributed under Creative Commons Attribution License [Attribution 4.0 International (CC BY 4.0)] 


\section{BACKGROUND}

Safe airway management is an essential skill for an anaesthesiologist. Laryngoscopy and endotracheal intubation are gold standard for securing the airway and giving positive pressure ventilation. Direct laryngoscopy has been used since many years as a conventional and routine method to facilitate this procedure.

Laryngoscopy and endotracheal intubation are mandatory for most patients undergoing operation under general anaesthesia which is invariably associated with certain cardiovascular changes such as tachycardia (average $20 \%$ ) or bradycardia, rise in blood pressure (> $30 \%$ ) and wide variety of cardiac arrhythmias.

Reid and Bruce in $1940^{1}$ and King Harris ${ }^{2}$ in 1951 described the circulatory response to laryngeal and tracheal intubation as reflex sympathoadrenal stimulation and showed that sympathetic reflex is provoked by the stimulation of epipharynx and larynx. The response is transient, occurring 30 seconds after intubation and lasting for less than 10 minutes.

The tachycardia and hypertensive response to laryngoscopy and intubation are not of much consequence and short lived in normotensive patients but may prove hazardous in patient with medical problems like hypertension, ischemic heart disease, thyrotoxicosis and cerebrovascular diseases where circulation is already jeopardised. ${ }^{3}$ Even a moderate increase in heart rate (15\%) is accompanied by a decrease in coronary perfusion pressure (17\%). In such cases acute left ventricular failure, acute myocardial ischemia and cerebral haemorrhage may occur. These changes may be fatal and sudden deaths have also been reported in patients with hypertension, ischemic heart disease and cerebrovascular diseases.

Haemodynamic stability is an integral and essential goal of anaesthetic management plan. Various methods and drugs ${ }^{4}$ have been used to attenuate the response to laryngoscopy and intubation. They are:

- Deep inhalation anaesthesia.

- $\quad$ Topical lignocaine $2 \%$.

- Lignocaine aerosol $10 \%$.

- Intravenous lignocaine $2 \%{ }^{5}$

- Vasodilators - IV sodium nitroprusside, IV nitro-glycerine and IV hydralazine.

- Opioids - IV fentanyl, IV sufentanil, IV alfentanil and IV remifentanil. 6

- $\quad$ Beta blockers - IV metoprolol, IV esmolol, IV propranolol and IV labetalol.

- Calcium channel blockers - sublingual and IV nifedipine, IV verapamil, IV diltiazem. ${ }^{7}$

- Alpha 2 adrenergic agonist - clonidine, dexmedetomidine.

- General anaesthetics - propofol.

Intravenous (IV) lignocaine is one of the oldest, cheapest and most easily available drugs used for attenuation of hemodynamic response to laryngoscopy and intubation.

Dexmedetomidine, introduced in 1999 for human use is a new selective alpha- 2 adrenergic agonist having 8-times more affinity for alpha-2 adrenoceptors as compared with clonidine.
Pre-treatment with dexmedetomidine attenuates haemodynamic response to laryngoscopy and intubation.

The present study was undertaken to compare the efficacy of $1.5 \mathrm{mg} \mathrm{/} \mathrm{kg}$ of IV lignocaine and $1 \mathrm{mcg} / \mathrm{kg}$ of dexmedetomidine IV infusion in attenuating the hemodynamic response to laryngoscopy and intubation.

\section{Objectives}

To evaluate the degree of cardiovascular response evoked by laryngoscopy and endotracheal intubation and compare the effectiveness of IV lignocaine $1.5 \mathrm{mg} \mathrm{/} \mathrm{kg}$ and IV dexmedetomidine $1 \mathrm{mcg} / \mathrm{kg}$ as a premedication in attenuating this cardiovascular response (in terms of heart rate, systolic blood pressure, diastolic blood pressure, mean arterial pressure, rate pressure products, oxygen saturation (spo2) in patients undergoing elective surgeries under general anaesthesia.

\section{METHODS}

This was a prospective randomised, comparative, clinical study conducted from $12^{\text {th }}$ February 2018 to $10^{\text {th }}$ February 2019. After approval by the institutional review board (IRB) committee \& written informed consent obtained from patients, 60 patients of group $\mathrm{L}$ and $\mathrm{D}$ belonging to American Society of Anesthesiologists (ASA) grade I / II who satisfied the inclusion criteria, scheduled for surgery under general anaesthesia were included in this study.

Sample size was calculated on the basis of previous studies.

1. King BD, Harris LC, Greifen stein FE et al. Reflex circulatory responses to direct laryngoscopy and tracheal intubation performed during general anaesthesia. ${ }^{2}$

2. Gangappa RC, Chanrashekharappa K, Mallappa K. A clinical study of intravenous dexmedetomidine versus lignocaine premedication for attenuation of haemodynamic responses to laryngoscopy and endotracheal intubation. ${ }^{8}$

\section{Inclusion Criteria}

- $\quad$ ASA grade I \& II.

- Age between 20 \& 60 years.

- $\quad$ Either sex.

\section{Exclusion Criteria}

- Those taking antihypertensive drugs.

- Patients with baseline HR < 60 BPM.

- History of asthma / reactive airway disease.

- $\quad$ Patients with cardiac, renal, hepatic, cerebral diseases.

- $\quad$ Obese, pregnant \& nursing women.

- Patients with anticipated difficult intubation.

- Patients requiring $>1$ attempt at intubation.

- Patients with history of sensitivity to drugs used in the study.

- Patients not willing to give consent. 


\section{Study Protocol}

Preoperative Assessment

Detailed history, physical and systemic examination of all patients was done on the day prior to operation.

Laboratory investigations like $\mathrm{CBC}$, renal function tests, liver function tests, blood sugar, serum electrolytes, urine analysis, X-ray chest and electrocardiogram (ECG) were reviewed. The nature of study \& procedure was explained to the patient. Written informed consent was taken from the patient.

\section{Preoperative Preparation}

All patients were kept nil by mouth at least for $6 \mathrm{hrs}$ before surgery. In the operation theatre, an intravenous line was secured \& pulse oximeter, non-invasive BP \& ECG were attached \& baseline readings were taken. All patients were premeditated with Inj. glycopyrrolate $0.004 \mathrm{mg} / \mathrm{kg}$ IV, Inj. ondansetron $0.08 \mathrm{mg} / \mathrm{kg}$ IV before preoxygenation.

All patients were randomly allocated into 2 groups. Randomisation was done using computer generated random number containing in opaque sealed envelope. Each group having thirty patients.

- Group L: Infusion of plain normal saline in $25 \mathrm{ml}$ over 10 minutes through infusion pump before induction \& 1.5 $\mathrm{mg} / \mathrm{kg}$ IV lignocaine diluted to $10 \mathrm{ml}$ with normal saline 3 minutes before intubation.

- Group D: Infusion of dexmedetomidine $1 \mathrm{mcg} / \mathrm{kg}$ diluted to $25 \mathrm{ml}$ in normal saline over 10 minutes through infusion pump before induction \& then $10 \mathrm{ml}$ normal saline 3 minutes before intubation.

All patients were preoxygenated with $100 \%$ oxygen. Respective study drug was injected as mentioned above. Patient was induced with Inj. thiopentone sodium $6 \mathrm{mg} / \mathrm{kg}$ IV \& Inj. suxamethonium $2 \mathrm{mg} / \mathrm{kg}$ IV. Patient was intubated with an endotracheal tube, maintained anaesthesia with 02 (50\%), N20 (50 \%), sevoflurane \& Inj. Vecuronium bromide $0.08 \mathrm{mg}$ / kg. HR, SBP, DBP, MAP and SPO2 were monitored \& RPP was calculated. All parameters were recorded at following stages:

- Base line

- After study drug

- At intubation

- $\quad$ L + 1 (after 1 minute of laryngoscopy)

- $\quad \mathrm{L}+3$ (after 3 minutes of laryngoscopy)

- $\quad \mathrm{L}+5$ (after 5 minutes of laryngoscopy)

- $\quad \mathrm{L}+7$ (after 7 minutes of laryngoscopy)

- $\mathrm{L}+10$ (after 10 minutes of laryngoscopy)
At the end of surgery, residual neuromuscular blockade was reversed with Inj. glycopyrrolate $0.008 \mathrm{mg} / \mathrm{kg}$ IV \& Inj. neostigmine $0.05 \mathrm{mg} / \mathrm{kg}$ IV

Extubation was carried out when the patient had adequately recovered from the effect of neuromuscular blockade with regular breathing pattern, good muscle tone / power, haemodynamic stability and was able to respond to verbal commands.

\section{Statistical Analysis}

Statistical analysis was done by using descriptive and inferential statistics using chi-square test, Students paired and unpaired t-test to find out the significance of the five variables namely mean heart rate, mean systolic blood pressure, mean diastolic blood pressure, mean arterial pressure and mean rate pressure product. Data analysis was carried out using Microsoft Excel spreadsheet and software online.

\section{RESULTS}

This study was conducted to evaluate and compare the efficacy of intravenous lignocaine and dexmedetomidine in attenuation of haemodynamic response to endotracheal intubation. Total sixty patients of either gender, belonging to ASA grade I or II were selected for study and divided in two groups, each group consisting of 30 patients each.

\section{Patients Demographics}

\begin{tabular}{|cccc|}
\hline \multicolumn{4}{c|}{ Demographic Details } \\
Patients' Data & Group L & Group D & P-Value \\
Number of patients & 30 & 30 & - \\
Age (years) & $38.3+8.7$ & $39.2+7.1$ & 0.6623 \\
Male: Female & $16: 14$ & $14: 16$ & - \\
Weight (kg) & $56.8+5.6$ & $58+6.6$ & 0.4507 \\
ASA grade I \& II & $20: 10$ & $20: 10$ & - \\
\hline Table 1. Insignificant Difference between the Two Groups with \\
Regard to Age, Sex, Weight \& ASA Grade. (P > 0.05) \\
\hline
\end{tabular}

Table 1 . Shows the age distribution of both the groups which is between 20 to 60 years with mean age of 38.3 years in lignocaine group and 39.2 years in dexmedetomidine group. Sex ratio of group lignocaine was 16 males and 14 females while that of dexmedetomidine group was 14 males and 16 females. In group L the mean weight was $56.8 \mathrm{kgs}$ and in group D the mean weight was 58 kgs.

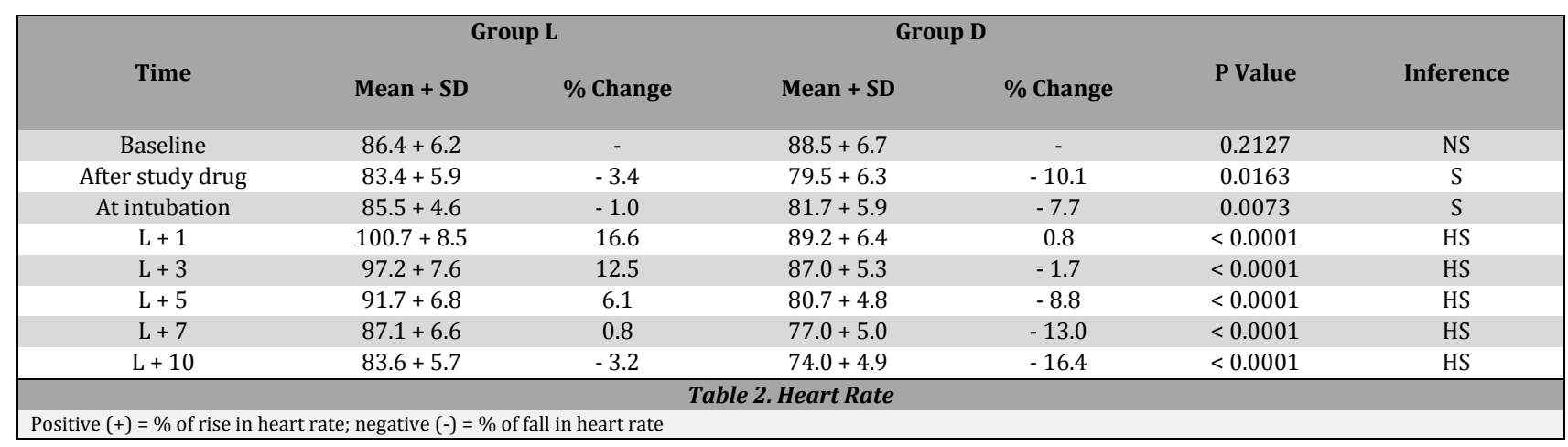




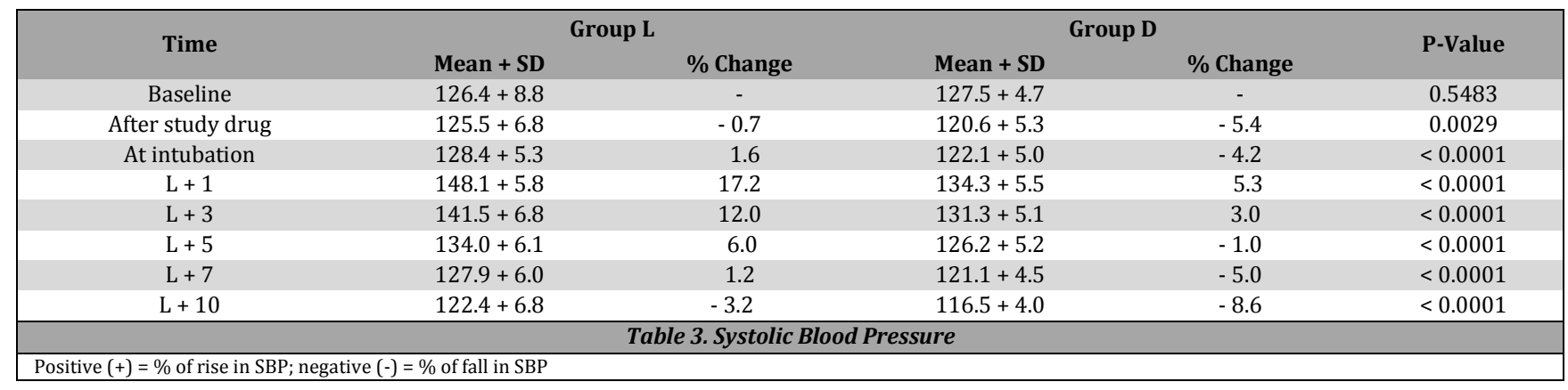

\begin{tabular}{|c|c|c|c|c|c|}
\hline \multirow{2}{*}{ ime } & \multicolumn{2}{|c|}{ Group L } & \multicolumn{2}{|c|}{ Group D } & \multirow{2}{*}{ P-Value } \\
\hline & Mean + SD & $\%$ Change & Mean + SD & \% Change & \\
\hline Baseline & $78.6+4.8$ & - & $79.3+5.1$ & - & 0.5862 \\
\hline After study drug & $73.4+5.2$ & -6.6 & $70.3+5.0$ & -11.3 & 0.0220 \\
\hline At intubation & $77.3+4.7$ & -1.7 & $74.1+4.3$ & -6.6 & 0.0079 \\
\hline $\mathrm{L}+1$ & $86.8+5.5$ & 10.4 & $81.7+5.0$ & 3.0 & 0.0004 \\
\hline $\mathrm{L}+3$ & $83.6+4.7$ & 6.4 & $80.3+4.7$ & 1.2 & 0.0086 \\
\hline $\mathrm{L}+5$ & $79.6+4.8$ & 1.3 & $76.3+4.5$ & -3.8 & 0.0080 \\
\hline $\mathrm{L}+7$ & $76.4+4.4$ & -2.8 & $74.1+3.7$ & -6.6 & 0.0325 \\
\hline $\mathrm{L}+10$ & $73.3+4.3$ & -6.7 & $70.4+3.4$ & -11.2 & 0.0053 \\
\hline \multicolumn{6}{|c|}{ Table 4. Diastolic Blood Pressure } \\
\hline
\end{tabular}

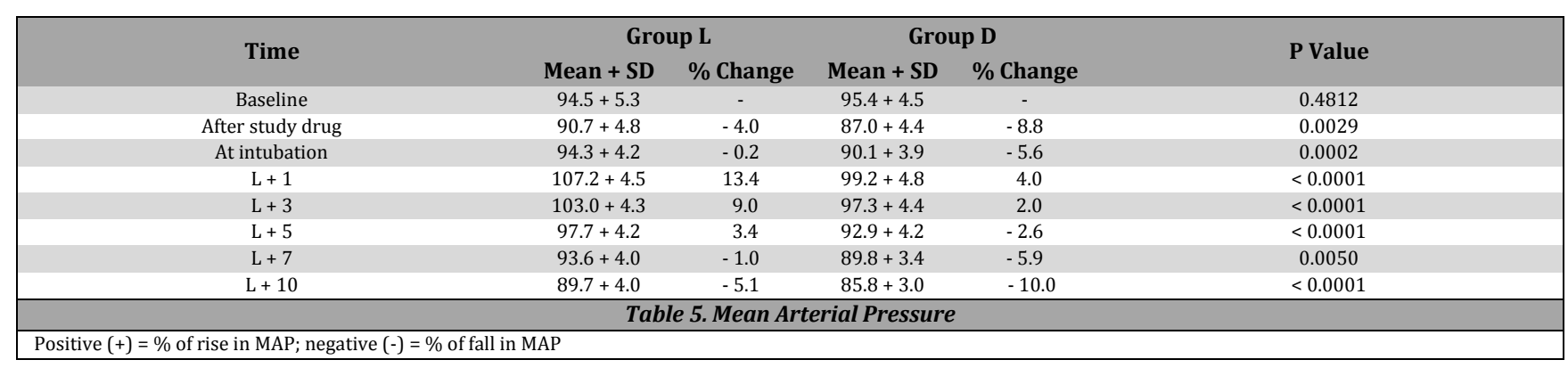

\begin{tabular}{|c|c|c|c|c|c|}
\hline \multirow{2}{*}{ Time } & \multicolumn{2}{|c|}{ Group L } & \multicolumn{2}{|c|}{ Group D } & \multirow{2}{*}{ P-Value } \\
\hline & Mean + SD & $\%$ Change & Mean + SD & \% Change & \\
\hline Baseline & $10940+1248$ & - & $11270+829$ & - & 0.2326 \\
\hline After study drug & $10475+1045$ & -0.3 & $9579+774$ & -15.0 & 0.0004 \\
\hline At intubation & $10985+854$ & 4.5 & $9971+669$ & -11.5 & $<0.0001$ \\
\hline $\mathrm{L}+1$ & $14914+1444$ & 41.9 & $11975+906$ & 6.3 & $<0.0001$ \\
\hline $\mathrm{L}+3$ & $13760+1273$ & 30.9 & $11417+737$ & 1.3 & $<0.0001$ \\
\hline $\mathrm{L}+5$ & $12294+1154$ & 17.0 & $10182+684$ & -9.6 & $<0.0001$ \\
\hline $\mathrm{L}+7$ & $11145+1067$ & 6.0 & $9309+618$ & -17.4 & $<0.0001$ \\
\hline $\mathrm{L}+10$ & $10244+1022$ & -2.5 & $8617+547$ & -23.5 & $<0.0001$ \\
\hline \multicolumn{6}{|c|}{ Table 6. Rate Pressure Product } \\
\hline
\end{tabular}

Heart rate in both groups at baseline was comparable and there was no statistical difference between them (P-value > 0.05). Heart rate after infusion of study drug, during laryngoscopy and intubation in dexmedetomidine group and lignocaine group was statistically different and significant (Pvalue $<0.05$ ). Heart rate at $1,3,5,7$ and 10 minutes after laryngoscopy in dexmedetomidine group and lignocaine group was statistically different and highly significant (P-value < 0.0001). Systolic blood pressure in both groups at baseline was comparable and there was no statistical difference between them (P-value $>0.05)$. Difference in systolic blood pressure after infusion of study drug between the two drugs was statistically different and significant ( $\mathrm{P}$-value $<0.05$ ). During laryngoscopy and intubation at $1,3,5,7 \& 10$ minutes thereafter, comparison of SBP in the dexmedetomidine group and lignocaine group was statistically different and highly significant (P-value $<0.0001$ ). Diastolic blood pressure in both groups at baseline was comparable as there was no statistical difference between them (P-value $>0.05)$. After infusion of study drug, laryngoscopy and intubation at 1, 3, 5, $7 \& 10$ minutes DBP in the dexmedetomidine group and lignocaine group was statistically different and significant (P-value < 0.05).

Mean arterial pressure in both groups at baseline was comparable as there was no statistical difference between them (P-value $>0.05$ ). After study drug infusion, laryngoscopy and intubation, at $7^{\text {th }}$ minute MAP in the dexmedetomidine group and lignocaine group was statistically different and significant $(\mathrm{P}$-value $<0.05)$. Whereas at $1,3,5$ and 10 minutes after laryngoscopy and intubation MAP in the dexmedetomidine group and lignocaine group was statistically different and highly significant $(\mathrm{P}$-value $<0.0001)$.

Rate pressure product in both groups at baseline was comparable as there was no statistical difference between them (P-value > 0.05). After study drug administration, comparison of rate pressure product in dexmedetomidine 
group and lignocaine group was statistically different (P-value $<0.05)$.

During laryngoscopy and intubation and thereafter at 1,3 , 5, 7 and 10 minutes, comparison of rate pressure product in dexmedetomidine group and lignocaine group was statistically different and highly significant (P-value $<0.0001$ ).

\section{DISCUSSION}

Laryngoscopy \& tracheal intubation are considered as the most critical events during general anaesthesia. In 1940 Reid LC, Brace et al. ${ }^{1}$ concluded that laryngoscopy \& intubation increases the cardiac workload and oxygen demand of myocardium. Stoelting R.K. ${ }^{5}$ showed that the duration of laryngoscopy (less than 15 seconds) was extremely important in minimising the magnitude \& duration of circulatory stimulation. Reema Goel et al. ${ }^{4}$ studied attenuation of cardiovascular response to laryngoscopy \& intubation by various drugs (beta blockers like esmolol and metoprolol).

Dexmedetomidine, a selective $\alpha 2$ adrenoceptor agonist, causes fall in BP \& HR, \& sedation \& analgesia. The fall in BP was mainly due to inhibition of central sympathetic outflow \& also due to stimulation of presynaptic $\alpha 2$ adrenoceptors decreasing norepinephrine release. An important advantage was its minimal respiratory depressant effect with potent sedative \& analgesic effects \& it's faster onset of action \& short half-life that allows effective titration of drug dose.

This prospective study was conducted to know whether dexmedetomidine, a newer $\alpha$ 2-agonist is effective for attenuating the hemodynamic response to laryngoscopy \& endotracheal intubation with the conventionally used agent lignocaine. The pre-operative HR \& BP of the two groups were having no significant difference $(P>0.05)$. After infusion of dexmedetomidine, there was a fall in HR and BP in the study group.

\section{Drug and Dosage}

In 1985, Stanley Tam ${ }^{9}$ concluded that $1.5 \mathrm{mg} / \mathrm{kg}$ lignocaine attenuates increase in BP \& HR only when given 3 min before intubation. We used the same dosage for lignocaine in our study. In 2014, Raval DL et al. ${ }^{10}$ did a comparative study of two different doses of dexmedetomidine $(0.5 \mathrm{mcg} / \mathrm{kg} \& 1 \mathrm{mcg} /$ $\mathrm{kg}$ ) on haemodynamic responses to induction of anaesthesia \& tracheal intubation \& concluded that dexmedetomidine $1 \mathrm{mcg}$ / kg was more effective than $0.5 \mathrm{mcg} / \mathrm{kg}$. We have used $1 \mathrm{mcg}$ / kg of dexmedetomidine in our study.

\section{Patient Demographics}

There was no statistically significant difference between the mean age (years) \& weight (kgs) \& gender distribution among both groups $(\mathrm{P}>0.05)$. (Table 1$)$

\section{Hemodynamic Parameters Heart Rate (Table 2)}

The results in our study are as following:

- HR of both groups at baseline had no statistical difference between them $(P>0.05)$.
- Following administration of study drugs, there was a fall in HR in both groups, group L $(-3.4 \%)$ and group D (- 10.1 $\%)$. The fall in HR reduced to $(-1.0 \%)$ in group $L$ and to ($7.7 \%$ in group D during laryngoscopy \& intubation. Which was statistically significant $(\mathrm{P}<0.05)$.

- In $\mathrm{L}+1$, there was a maximum rise in HR from baseline in both groups, more with group L (16.6 \%) than group D $(0.8 \%)$ so it was statistically highly significant $(\mathrm{P}<$ 0.0001).

- At L + 3, L + 5 and L + 7 HR in both groups started falling from $L+1$. However, there was a rise in HR from baseline in group $\mathrm{L}(12.5 \%, 6.1 \%$ and $0.8 \%)$ and fall from baseline in group D (- $1.7 \%,-8.8 \%$ and $-13.0 \%)$ respectively which was statistically highly significant $(\mathrm{P}<0.0001)$.

- At L + 10 HR in both groups was below baseline, (- $3.2 \%)$ in group L \& (- $16.4 \%)$ in group $\mathrm{D}$, difference was statistically highly significant $(\mathrm{P}<0.0001)$.

The results of our study were similar to those carried out by-

1. Malde A et al. ${ }^{11}$ concluded that lignocaine \& fentanyl both attenuated the rise in pulse rate. In our study also HR reduced after administration of lignocaine which correlates with their study.

2. Gangappa RC et al. ${ }^{8}$ A clinical study of intravenous dexmedetomidine $(1 \mathrm{mcg} / \mathrm{kg}$ ) versus lignocaine $(1.5 \mathrm{mg}$ / kg) premedication for attenuation of haemodynamic responses to laryngoscopy and endotracheal intubation. They concluded that dexmedetomidine is more effective than lignocaine.

\section{Systolic Blood Pressure (Table 3)}

The results in our study are as following:

- SBP of both groups at baseline was comparable to each other and there was no statistical difference between them $(\mathrm{P}>0.05)$.

- Following administration of study drugs, there was a fall in SBP in both groups, group L (- $0.7 \%)$ and group D (- 5.4 $\%)$ and was statistically significant $(\mathrm{P}<0.05)$.

- SBP increased by (1.6 \%) in group L and reduced by $(-4.2$ $\%$ ) in group D from baseline during laryngoscopy and intubation. This difference was statistically highly significant $(\mathrm{P}<0.0001)$.

- In $\mathrm{L}+1$, there was a maximum rise in HR from baseline in both groups, more with group L $(17.2 \%)$ than group D $(5.3 \%)$ so it was statistically highly significant $(\mathrm{P}<$ 0.0001).

- At $\mathrm{L}+3, \mathrm{~L}+5$ and $\mathrm{L}+7 \mathrm{SBP}$ in both groups started falling from $L+1$. However, it was still above baseline in group $L$ $(12.0 \%, 6.0 \%$ and $1.2 \%)$ respectively, while in group D it was above baseline at $\mathrm{L}+3(3.0 \%)$ and decreased below baseline at $\mathrm{L}+5$ and $\mathrm{L}+7$ (- $1.0 \%$ and $-5.0 \%)$ respectively which was statistically highly significant $(\mathrm{P}<$ 0.0001 ) in favour of dexmedetomidine.

- At L + 10 SBP in both groups was below baseline, (- $3.2 \%)$ in group $\mathrm{L}$ and $(-8.6 \%$ ) in group $\mathrm{D}$, difference was statistically highly significant $(\mathrm{P}<0.0001)$.

The results of our study are similar to those carried out by-

1. J.M. Campbell et al. ${ }^{12}$ have shown that IV lignocaine $1.5 \mathrm{mg}$ / kg offered complete attenuation against post intubation rise in HR and arterial BP when given 3 min prior to intubation. 
2. Singh $\mathrm{G}$ et al. ${ }^{13}$ concluded that dexmedetomidine $(1 \mathrm{mcg} /$ $\mathrm{kg}$ ) was more effective in blunting the SBP to laryngoscopy and endotracheal intubation as compared to lignocaine $(1.5 \mathrm{mg} / \mathrm{kg}$ ), which correlates with our study.

\section{Diastolic Blood Pressure (Table 4)}

The results in our study are as following:

- DBP of both groups at baseline was comparable to each other \& there was no statistical difference between them (P > 0.05).

- Following administration of study drugs, there was a fall in DBP in both groups, group L (- $6.6 \%)$ \& group D (- 11.3 $\%)$. The fall in DBP reduced to $(-1.7 \%)$ in group $L$ \& (- 6.6 $\%$ ) in group D during laryngoscopy \& intubation. This difference was statistically significant $(\mathrm{P}<0.05)$.

- At $L+1$, there was a maximum rise in SBP from baseline in both groups, more with group L (10.4\%) than group D (3.0\%), so it was statistically significant $(\mathrm{P}<0.05)$.

- At $\mathrm{L}+3$ DBP in both groups started falling from $\mathrm{L}+1$. However, it was still above baseline in group L (6.4\%) \& in group D (1.2\%), which was statistically significant $(\mathrm{P}<$ $0.05)$.

- At L + 5 DBP was above baseline in group L (1.3\%) \& below baseline in group D (- $3.8 \%)$. The difference was statistically significant $(\mathrm{P}<0.05)$.

- At L + 7 \& L + 10 DBP in both groups was below baseline, in group L $(-2.8 \% \&-6.7 \%) \&$ in group D (- $6.6 \%$ \& $11.2 \%)$ respectively, difference was statistically significant $(\mathrm{P}<0.05)$.

by:

The results of our study were similar to those carried out

1. Keniya VM et al. ${ }^{14}$ showed that $1 \mathrm{mcg} / \mathrm{kg}$ dexmedetomidine effectively attenuated the press or response to laryngoscopy \& subsequent intubation, where the dexmedetomidine group was compared to the control group. After intubation, the maximal average increase was $8 \%$ in SBP and $11 \%$ in DBP, compared to $40 \%$ and $25 \%$, respectively, in the control group, which correlates with our study.

2. Surabathuni $\mathrm{S}$ et al. concluded that dexmedetomidine 1 $\mathrm{mcg} / \mathrm{kg}$ \& lignocaine $1.5 \mathrm{mg} / \mathrm{kg}$ were effective in blunting the DBP to intubation, but dexmedetomidine was superior in blunting the haemodynamic response to laryngoscopy \& endotracheal intubation, which correlates with our study.

Mean Arterial Pressure (Table 5)

The results in our study are as following:

- MAP of both groups at baseline was comparable to each other \& no statistical difference between them $(\mathrm{P}>0.05)$.

- Following administration of study drug \& laryngoscopy \& intubation, there was a fall in MAP in both groups, group L (- $4.0 \%$ \& $-0.2 \%)$ \& group D (- $8.8 \%$ \& $-5.6 \%)$ respectively. Which was statistically significant $(\mathrm{P}<0.05)$.

- At $\mathrm{L}+1 \& \mathrm{~L}+3$, there was a maximum rise in MAP from baseline in both groups, more with group L $(13.4 \%$ \& 9.0 $\%)$ than group D (4.0\% \& $2.0 \%$ ) respectively, which was statistically highly significant $(\mathrm{P}<0.0001)$.

- At L + 5 MAP was still above baseline in group L (3.4\%) \& below baseline in group D (- $2.6 \%)$, which was statistically highly significant $(\mathrm{P}<0.0001)$.
- At L + 7 MAP in both groups went below baseline, in group L (- $1.0 \%) \&$ in group D (- $5.9 \%)$, difference was statistically significant $(\mathrm{P}<0.05)$.

- At L + $10 \mathrm{MAP}$ in both groups was below baseline, in group L (- $5.1 \%) \&$ in group D (- $10.0 \%)$, difference was statistically highly significant $(\mathrm{P}<0.0001)$.

The results of our study were similar to those carried out by-

1. Samala $\mathrm{S}$ et al. ${ }^{15}$ concluded that dexmedetomidine $1 \mathrm{mcg}$ / kg was superior to lignocaine $1.5 \mathrm{mg} / \mathrm{kg}$ in blunting the MAP to laryngoscopy \& endotracheal intubation without any significant side effects, which correlates with our study.

2. Kalakeri et al. ${ }^{16}$ showed that dexmedetomidine $(1 \mu \mathrm{g} / \mathrm{kg})$ attenuates MAP compared to basal value after drug infusion \& before induction. MAP remained lower than the baseline value even after the intubation. These findings correlate with our study.

\section{Rate Pressure Product (Table 6)}

The results in our study are as following:

- RPP of both groups at baseline was comparable to each other \& no statistical difference was present between them $(\mathrm{P}>0.05)$.

- Following administration of study drugs there was a fall in RPP in both groups, group L (- $0.3 \%)$ \& group D (- 15.0 $\%)$. This difference was statistically significant $(\mathrm{P}<0.05)$.

- During laryngoscopy \& intubation, RPP increased above baseline in group L ( $4.5 \%$ ), but in group D, RPP was still below baseline (-11.5\%). Which was statistically highly significant $(\mathrm{P}<0.0001)$.

- At $L+1 \& L+3$, there was a maximum rise in RPP from baseline in both groups, more with group L $(41.9 \%$ \& 30.9 $\%)$ than group D (6.3 \% \& $1.3 \%)$ respectively, which was statistically highly significant $(\mathrm{P}<0.0001)$.

- At L + 5 \& L + 7 RPP was still above baseline in group L $(17.0 \% \& 6.0 \%)$ and below baseline in group D (- $9.6 \%$ \& $-17.4 \%)$ respectively, which was statistically highly significant $(\mathrm{P}<0.0001)$.

- At L + 10 MAP in both groups was below baseline, in group L $(-2.5 \%)$ \& in group D (- $23.5 \%)$, difference was statistically highly significant $(\mathrm{P}<0.0001)$.

The result of our study was similar to those carried out by

1. Kapdi MS et al. ${ }^{17}$ studied the comparison of dexmedetomidine ( $1 \mathrm{mcg} / \mathrm{kg}$ ) over 10 mins through infusion pump \& found that RPP decreased at $0,1,2,3,4$, \& 5 mins from baseline in dexmedetomidine group.

2. Sale HK et al. ${ }^{18} \&$ Gangappa RC et al. ${ }^{8}$ concluded that efficacy of dexmedetomidine ( $1 \mathrm{mcg} / \mathrm{kg}$ ) in attenuation of the pressor response to laryngoscopy \& intubation compared to lignocaine $(1.5 \mathrm{mg} / \mathrm{kg}$ ) was significantly higher in ASA I and II patients with respect to HR, SBP, DBP and MAP, which correlates with our study.

$\mathrm{SpO}_{2}$ - All patients in each group had normal arterial saturation throughout the study.

ECG: In present study no abnormal changes were recorded in any patient throughout the procedure. Burstein CL et al.19 had similar findings as compared to our study. 


\section{CONCLUSIONS}

Dexmedetomidine provides better blunting of stress response during laryngoscopy and intubation without causing clinically significant respiratory depression, bradycardia or hypotension. It is better in achieving a low RPP, which is a good predictor of myocardial oxygen consumption. Dexmedetomidine provides better cardio-protection in patients against pressure response than lignocaine.

In conclusion, dexmedetomidine ( $1 \mathrm{mcg} / \mathrm{kg}$ ) was found to be superior to lignocaine $(1.5 \mathrm{mg} / \mathrm{kg}$ ) for attenuation of pressor response.

\section{Limitations \\ We did not measure the plasma catecholamine levels which is an objective means of measuring hemodynamic stress response.}

Data sharing statement provided by the authors is available with the full text of this article at jemds.com.

Financial or other competing interests: None.

Disclosure forms provided by the authors are available with the full text of this article at jemds.com.

\section{REFERENCES}

[1] Reid LC, Brace DE. Irritation of the respiratory tract and its reflex effect upon heart. Surg Gynecol Obstet 1940;70:157-62.

[2] King BD, Harris LC, Greifenstein FE, et al. Reflex circulatory responses to direct laryngoscopy and tracheal intubation performed during general anesthesia. Anesthesiology 1951;12(5):556-66.

[3] Surabathuni S, Santhilatha GR, Rao PN, et al. To evaluate the effect of intravenous dexmedetomidine $(1 \mu \mathrm{g} / \mathrm{kg})$ as premedication in obtunding the pressor response to laryngoscopy and tracheal intubation compared to intravenous preservative free $2 \%$ lignocaine (1.5$2 \mathrm{mg} / \mathrm{kg}$ ). Journal of Dental and Medical Sciences 2015;14(9):37-43.

[4] Goel R, Rani R, Singh OP, et al. Attenuation of cardiovascular responses to laryngoscopy and intubation by various drugs in normotensive patients. Hospital Today 2000:9.

[5] Stoelting RK. Blood pressure and heart rate changes during short-duration laryngoscopy for tracheal intubation: influence of viscous or intravenous lidocaine. Anesth Analg 1978;57(2):197-9.

[6] Mireskandari SM, Abulahrar N, Darabi ME, et al. Comparison of the effect of fentanyl, sufentanil, alfentanil and remifentanil on cardiovascular response to tracheal intubation in children. Iran J Pediatr 2011;21(2):173-80.
[7] Forbes AM, Dally FG. Acute hypertension during induction of anaesthesia and endotracheal intubation in normotensive man. Br J Anaesth 1970;42(7):618-24.

[8] Gangappa RC, Chandrashekharappa K, Mallappa K. A clinical study of intravenous dexmedetomidine versus lignocaine premedication for attenuation of haemodynamic responses to laryngoscopy and endotracheal intubation. J Evid Based Med Healthc 2016;3(64):3470-5.

[9] Tam S, Chung F, Campbell M. Intravenous lidocaine: optimal time of injection before tracheal intubation. Anesth Analg 1987;66(10):1036-8.

[10] Raval DL, Yadav VP. A comparative study of two different doses of dexmedetomidine on haemodynamic responses to induction of anaesthesia and tracheal intubation. J Clin Exp Res 2014;2(3):163-8.

[11] Malde AD, Sarode V. Attenuation of the hemodynamic response to endotracheal intubation: fentanyl versus lignocaine. The Internet Journal of Anesthesiology 2006;12(1).

[12] Tam S, Chung F, Campbell JM. Attenuation of circulatory responses to endotracheal intubation using intravenous lidocaine-a determination of the optimal time of injection. Canadian Anaesthetists Society Journal 1985;32(3):S65.

[13] Singh G, Kaur H, Aggarwal S, et al. Intravenous dexmedetomidine vs. lignocaine in attenuating the hemodynamic responses during laryngoscopy and endotracheal intubation: a randomized double blind study. Anaesthesia, Pain \& Intensive Care 2019;21(2):181-6.

[14] Keniya VM, Ladi S, Naphade R. Dexmedetomidine attenuates sympathoadrenal response to tracheal intubation and reduces perioperative anaesthetic requirement. Indian J Anaesth 2011;55(4):352-7.

[15] Samala S, Indurkar PS. Effect of intravenous dexmedetomidine $(1 \mu \mathrm{g} / \mathrm{kg})$ in obtunding the pressor response to laryngoscopy and tracheal intubation compared to intravenous preservative free $2 \%$ lignocaine (1.5 mg/kg). Int J Res Med Sci 2016;4(7):2750-55.

[16] Kalakeri S, Suresh C. Dexmedetomidine as an adjunct to anaesthetic induction to attenuate hemodynamic response to endotracheal intubation in patients undergoing CABG. Int J Curr Res Aca Rev 2015;3(4):10117.

[17] Panchal M, Kapdi M, Sardhara N, et al. Comparative study of dexmedetomidine or MGSO4 to attenuate hemodynamic stress response to laryngoscopy and intubation. Indian Journal of Applied Basic Medical Sciences 2018;30(20A):1045-7.

[18] Sale HK, Shendage VJ. Lignocaine and dexmedetomidine in attenuation of pressor response to laryngoscopy and intubation: a prospective study. International Journal of Scientific Study 2015;3(9):155-60.

[19] Burstein CL, Lopinto FJ, Newman W. Electrocardiographic studies during endotracheal intubation. I. Effects during usual routine techniques. Anesthesiology 1950;11(2):224-37. 